\title{
PROCEDIMENTOS EM BIOSSEGURANÇA NA TUBERCULOSE
}

\author{
Paulo Marcelo T. Cotias*
}

\section{Resumo}

Na avaliação realizada se conclui que as formas usadas pela Segurança Biológica para lidar com a Tuberculose, são praticamente, iguais as usadas nas demais doenças infecciosas. Se torna importante ser criada e praticada, em cada Unidade Hospitalar, uma nova filosofia neste sentido, através de treinamento e de educação continuada para todos os profissionais que integram a unidade, sem exceção. Os novos hábitos de Segurança Biológica e Ambiental devem ser incorporados na rotina, não só no atendimento em geral, mas nas atividades de todos os setores como ambulatório, enfermaria, farmácia, nutrição, incluindo até a limpeza. O uso de Equipamentos de Proteção Individuais (EPI's) é uma forma de defesa contra as contaminações e acidentes de trabalho. Estar sempre atento as novas metodologias e formas profiláticas faz com que a segurança no trabalho médico tenha sucesso e continuidade, preservando a relação profissional e paciente.

Palavras chave: tuberculose; medidas de controle; prevenção

\section{Summary}

Evaluation indicates that Biological Security strategies to deal with tuberculosis are practically identical to the ones in used in the rest of the infectious diseases. It is important to create and to implement a new philosophy on biosafety in each health unit, through continued education for all health professionals who work in the unit, without exception. The new strategies for Biological and Ambient Security must be incorporated in the routine, not only in the patient related activities, but in all areas, such as in and out-patients units, laboratory, pharmacy, nutrition, including until the cleanness actions. Using the Individual Equipment of Protection is a form of defense against contamination and work-related accidents. Being aware of the new methodologies and prophylactic actions makes medical work secure and successful, preserving the patient-health professional relationship.

Key words: tuberculosis; infection control measures; prevention 


\section{Histórico}

O inicio dos hospitais se deu na Idade Média, afim de atender os pobres e isso foi feito pelos religiosos católicos em mosteiros.

$\mathrm{Na}$ Europa, nos séculos XVIII e IXX, começaram os Hospitais Gerais onde eram atendidos os pacientes de menor poder aquisitivo. O atendimento de enfermagem era feito por irmãs religiosas.

Pode-se dizer que os primeiros cuidados médicos de Biossegurança datam de 1860, quando o obstetra austríaco Ignez Semmelweiss conseguiu diminuir a infecção puerperal pela lavagem das mãos com água e sabão, antes do procedimento do parto.

Em 1869, James Simpson, médico escocês, demonstrou, através de estudos comparativos, altas taxas de mortalidade nos hospitais de grande porte em relação aos de pequeno e médio porte.

Já em meados do século XIX, William Far e Florence Nightingale realizaram os primeiros estudos estatísticos e epidemiológicos em hospitais ingleses, demonstrando que havia um índice muito alto de óbitos nos grandes hospitais.

Em 1946 com o advento dos antimicrobianos parecia que as infeccões responsáveis pelo maior número destes óbitos, haviam sido debeladas.

Contudo, em 1950, com o surto de estafilococos resistentes passou-se a acreditar que os antimicrobianos não erradicavam todas as infecções. Somaram-se a isso as novas técnicas propedêuticas, terapias invasivas, além da biotecnologia e novas drogas imunossupressoras que entraram no arsenal terapêutico no final do século XX e início do XXI. Assim, tornou-se importante, a cada momento, manter um controle das infecções hospitalares.

\section{Origem}

Existem motivos que concorrem para que haja certo descaso no modo de se trabalhar, levando a um descontrole e, portanto, à quebra de barreiras de muito agentes microbianos.
Tome-se como exemplo a chamada "banalização do branco", quando uniformes ou roupas usadas no interior de ambientes hospitalares são levados para ambientes externos, acarreando muitas contaminações.

Estas ocorrências e muitas outras se dão por inexperiência e negligência, devido a falta de informação, mau estado dos equipamentos e deficiência de organização ou desarmonia no trabalho.

\section{Biossegurança}

Consideramos, hoje, que a Biossegurança é a parte da Medicina do Trabalho que trata das medidas destinadas a preservar a qualidade de vida do trabalhador. Atualmente tem enfoque epidemiológico, incorporando a visão do acidente biológico. Que é definido pela OMS como qualquer lesão física ou psíquica conhecida.

\section{Regulamentação}

No Brasil, a Biossegurança está estabelecida pela Lei N. ${ }^{\circ} 8974$ de 05/01/95, que regulamenta os incisivos II e IV do parágrafo 1 do Artigo 255 da Constituição Federal e define normas técnicas para criar a Comissão Técnica Nacional de Biossegurança.

\section{Precauções}

Existem regras básicas de educação e higiene, antes chamadas de Precaução Universal e atualmente de Precaução Básica. São portanto medidas de prevenção para evitar acidentes e contaminações em qualquer tipo de trabalho.

Estas medidas incluem a utilização de Equipamentos de Proteção Individual (EPI's) e Equipamentos de Proteção Comum (EPC's). Podemos exemplificar que os EPI's são luvas, máscaras, capotes, etc. e os $E P C$ 's são sacos plásticos, caixas inox, caixas especiais com material resistente, etc. 


\section{Materiais}

É importante chamar a atenção para o manuseio de materiais contaminados, principalmente os pérfuro-cortantes (percentualmente, os que provocam a maioria dos acidentes de trabalho) como agulhas, seringas, scalps, lâminas, bisturis, além de material geral como gazes, luvas, curativos, papel de limpeza e outros. Estes materiais devem ter cuidados especiais quando vão ser descartados, pois existe perigo de contágio do pessoal da limpeza, caso não estejam bem acondicionados. O material descartado, pode ser acondicionado em caixas especiais, revestidas com material resistente, com tampa e deverá ser esterilizado em autoclave e posteriormente desprezado como lixo hospitalar.

\section{Rotinas}

Segundo trate-se de Hospitais, Postos, Laboratórios, as rotinas sofrerão variações, de acordo com a Comissão de Biosssegurança de cada um. Porém todos devem ter uma rotina ou Procedimentos Operacionais Padrões $\left(P O P^{\prime} s\right)$ que atendam à Segurança do Trabalho, exigida por lei. Estes POP's devem conter as rotinas de cada Serviço, descritas de modo claro e compreensivo.. Nelas devem ser citadas

- Limpeza, usando o meio universal (água e sabão) e químicos como o Cloro, Álcool Iodado (ação esporocida), Fenol Quartenário, Água oxigenada (desinfectante poderoso).

- Regras básicas, como higienização das mãos, descontaminação periódica dos materiais e locais de trabalho, proibição de comer, fumar, usar cosméticos, jóias, alimentos no local de trabalho.

- Regras Especiais, o relato de qualquer acidente ocorrido, coleta periódica de material dos funcionários, incluindo Inquéritos Tuberculínicos com Esquema de Vacinação, o uso de Cabines de Segurança Biológica, uso de roupas protetoras, limitadas para partes internas dos Serviços. Estimular o trabalho em dupla, evitando o uso de objetos comuns como telefones, canetas, puxadores, etc. Devem ser mantidos cuidados especiais de Engenharia de Biossegurança como o tipo especial de recobrimento das bancadas, portas com abertura para fora, instalação de lava-olhos, chuveiros para qualquer acidente.

Deve ser mantida a sinalização dos níveis de risco dos agentes manipulados como indicado abaixo:

I - Baixo risco individual e para a comunidade

II - Moderado risco individual e limitado para a comunidade

III - Alto risco individual e baixo para a comunidade

IV - Alto risco individual e para a comunidade

\section{Legislação}

Do ponto de vista da legislação a Lei $\mathrm{N}^{\circ}$ 8.112, regula o acidente de trabalho nos Artigos 211 a 214, sendo que, classificado o fato como Acidente de Trabalho, deverá ser comunicado em até 10 dias após o ocorrido, no caso de funcionários que são regidos pelo Regime Jurídico Único. No caso dos funcionários que são regidos pela Legislação Privada esta comunicação deverá ser feita em 24 horas, através do Formulário CAT (Comunicação de Acidente de Trabalho).

A medicação, também, é disponibilizada pelo local de trabalho, seja público ou privado, amparada pelo Artigo N. ${ }^{\circ} 213$ da RJU da União.

\section{Bibliografia}

Cotias, PMT et al.- Procedimentos Operacionais Padrões (POP's) na Avaliação e Conduta do Acidente com Material Biológico. Anais do II Congresso Brasileiro de Biossegurança 188-9 ; 2001.

Júnior, PSB; Wakimoto, M e Cotias, PMT -Biossegurança e Hospital: Dimensões Psicossocial do Risco entre Profissionais de Saúde. Rev. Feuduc/CEPEA/PIBIC,03:07-11;2001.

Mahler, DA: Loke, $\mathrm{J}$ - The pulmonary function laboratory. Clin. Ches. Med.10:129-33; 1999.

Regime Jurídico Único - Servidores Públicos Civis da União Lei *.112/90, D.O. U. 18/03/98 -Seção 1.

Resolução N. ${ }^{\circ}$ 10, 23/12/1999 - D. O U. Nº77 - Seção I Ministério da Previdência da Assistência Social - INSS - Brasília 20/04/00.

Teixeira, P.- Biossegurança uma abordagem multidiciplinar. Editora FIOCRUZ- Rio de Janeiro: Fiocruz; 1996 